\title{
Rancang Bangun Sistem Informasi Shipbroker Sebagai Media Transaksi Sewa Menyewa Kapal Berbasis Web
}

\author{
Syarif Hidayatulloh', Ummu Radiyah², Fauzan Khairo Umma ${ }^{3}$ \\ 1,2,3 Universitas Nusa Mandiri

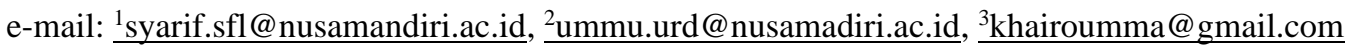

\begin{tabular}{ccc}
\hline Diterima & Direvisi & Disetujui \\
$29-04-2021$ & $18-05-2021$ & $02-06-2021$ \\
\hline
\end{tabular}

\begin{abstract}
Abstrak - PT Samudera Perdana Transpotama adalah sebuah perusahaan yang bergerak di bidang jasa pengurusan transportasi. Perusahaan ini menggunakan email sebagai media komunikasi. Begitu banyak email yang masuk sehingga mengakibatkan lambatnya proses mediasi dalam mencocokan permintaan antara pihak pemilik kapal dan penyewa. Pengembangan media berupa aplikasi berbasis website merupakan solusi terbaik untuk perusahaan ini agar lebih maju dan profesional. Model pengembangan sistem yang dilakukan adalah dengan menggunakan metode Waterfall atau disebut juga Classic Life Cycle. Bahasa pemrograman yang dipakai untuk pembuatan sistem ini adalah PHP. Untuk bagian desain menggunakan Jquery dan Bootstrap. Pada penyimpanan dan pengolahan data menggunakan database MySQL. Penelitian ini bertujuan untuk membuat aplikasi yang dapat memudahkan mediator dan perusahaan dalam menjalankan proses bisnisnya. Hasil dari penelitian ini yaitu membangun suatu sistem aplikasi Shipbroker berbasis web pada PT Samudera Perdana Transpotama, dengan adanya sistem ini user dapat menawarkan kapalnya untuk disewakan dan juga user dapat mencari kapal yang ingin di sewa sesuai kebutuhannya.
\end{abstract}

Kata Kunci: shipbroker, website, waterfall

\begin{abstract}
PT Samudera Perdana Transpotama is a company engaged in transportation management services. This company uses email as a medium of communication. So many incoming emails that resulted in the slow process of mediation in matching requests between the ship owner and charterer. Media development in the form of website-based applications is the best solution for this company to be more advanced and professional. The system development model used is the Waterfall method or also known as the Classic Life Cycle. The programming language used for this system is PHP. For the design part using Jquery and Bootstrap. On the storage and processing of data using a MySQL database. This study aims to create an application that can facilitate mediators and companies in carrying out their business processes. The result of this research is to build a web-based Shipbroker application system at PT Samudera Perdana Transpotama, with this system the user can offer his ship for rent and also the user can search for the ship he wants to rent according to his needs.
\end{abstract}

Keywords: shipbroker, website, waterfall

\section{PENDAHULUAN}

PT Samudera Perdana Transpotama adalah perusahaan yang bergerak di bidang jasa kepengurusan transportasi. Layanan yang ditawarkan oleh PT Samudera Perdana Transpotama meliputi beberapa divisi salah satunya adalah shipbroker \& chartering. Adapun pekerjaan pada divisi ini ialah sebagai perantara antara pemilik kapal dengan penyewa kapal. Masalah yang dapat timbul terkait sistem sewa yang ada diantaranya penyewa kesulitan dalam pencarian kendaraan untuk disewa dan memerlukan waktu cukup lama, selain itu juga penyewa mendapatkan informasi harga kendaraan yang tidak konsisten. Sistem yang digunakan saat ini masih menggunakan media email dan terdapat 100 (seratus) sampai dengan 200 (dua ratus) email masuk perhari untuk semua permintaan diantaranya adalah sewa menyewa kapal, jual beli kapal, dan muatan kapal. Oleh karena itu dibutuhkan sebuah media untuk berkomunikasi dan bertransaksi agar penyewa mendapatkan informasi serta pelayanan terbaik, efektif dan efisien.

Perkembangan teknologi dalam bidang sistem informasi berbasis web sudah berkembang kian pesat. Aplikasi berbasis web dibuat bukan hanya untuk penyedia informasi akan tetapi juga bisa digunakan untuk mengkomunikasikan hasil penelitian yang dipublikasikan secara online, karena bisa memudahkan pengguna dalam hal mengaksesnya (Pranata, Hamdani, \& Khairina, 2015). Sebuah website Toko Online dapat memudahkan pelaku usaha atau toko mempromosikan produknya dan mempermudah konsumen untuk mendapatkan informasi tentang produk-produk yang dimiliki penjual atau toko 
(Susilo \& Kurniati, 2018). Pengembangan sistem informasi yang dilakukan untuk pengelolaan kegiatan Praktek Kerja Lapangan di PT. Pegadaian menghasilkan kecepatan, ketepatan dan keakuratan dalam melakukan proses registrasi untuk mengikuti PKL, menampilkan informasi yang dibutuhkan, serta memanipulasi data yang akan digunakan dalam kegiatan PKL (Ayu \& Permatasari, 2018). Sebuah aplikasi RentPal yang dikembangkan melalui gabungan antara konsep web portal dengan proses bisnis jasa penyewaan barang digunakan sebagai platform untuk mempertemukan antara jasa penyewaan dengan penyewa barang dengan tujuan sebagai pencegahan tindakan kecurangan yang dilakukan penyewa (Zahra, Pradana, \& Jonemaro, 2019). Sistem informasi berbasis web sebagai wadah dimana transaksi sewa dapat berjalan secara online (Gunadi \& Zakaria, 2018).

Oleh karena itu untuk menyelesaikan masalah yang terjadi pada PT Samudra Perdana Transportama yaitu dengan membangun sebuah sistem informasi berbasis web yang akan menjadi media transaksi antara pemilik dan penyewa dari kapal tersebut. Web ini akan didukung dengan fiturfitur yang akan membantu dalam proses transaksi sewa, seperti adanya pengelompokan barang per kategori, keterangan barang yang akan disewa agar sesuai dengan keinginan, fitur pesan agar antara pihak penyedia jasa sewa dan penyewa dapat berinteraksi sehingga adanya pertukaran informasi secara langsung (Gunadi \& Zakaria, 2018).

\section{METODE PENELITIAN}

Metode penelitian yang dilakukan dalam pengembangan sistem ini menggunakan metode Waterfall atau disebut juga dengan Classic Life Cycle. Model Classic Life Cycle air terjun (waterfall) atau sering juga disebut model sekuensial linier (sequential linear) atau alur hidup klasik. Model waterfall menyediakan pendekatan dengan alur hidup perangkat lunak (software) secara sekuensial atau berurut dimulai dari analisis, desain atau perancangan, pengodean, pengujian, dan tahap pendukung (support) (Ariani Sukamto \& Shalahuddin, 2013).

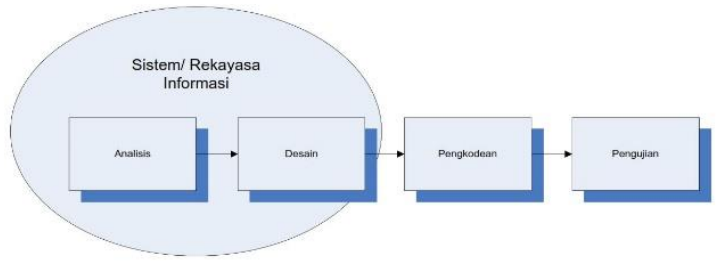

Sumber: (Ariani Sukamto \& Shalahuddin, 2013) Gambar 1. Metode Waterfall

a. Analisis

Merupakan tahapan untuk mencari hal yang dibutuhkan pengguna dalam menggunakan aplikasi, setelah itu akan didapatkan spesifikasi sistem yang nantinya akan dibutuhkan dan dibuatkan program aplikasi yang akan digunakan. Pengaturan akses untuk admin dan user dianalisis lagi kebutuhannya yaitu untuk admin mendapatkan hak akses penuh dalam mengelola website, Sedangkan user tidak bisa login ke halaman admin, hanya bisa akses sebagai user yang menawarkan atau menyewa serta berkomunikasi dengan user lain. Dalam langkah ini terdapat analisa yang dilakukan terhadap kebutuhan sistem. Pengumpulan data dalam tahapan ini akan dilakukan sebuah pengamatan, wawancara atau study literatur (Tristianto, 2018).

b. Design

Proses ini akan menerjemahkan syarat kebutuhan kedalam sebuah perancangan perangkat lunak yang akan diperkirakan sebelum mengimplementasikannya kedalam pemrograman (Tristianto, 2018). Pada tahapan ini akan dilakukan perancangan database dalam bentuk ERD (Entity Relationship Diagram) dengan menggunakan creatly. Untuk desain arsitektur perangkat lunak menggunakan software Umlet. Desain ini dibuat berdasarkan kebutuhan aplikasi pada PT. Samudra Perdana Transportama.

c. Pengkodean

Tahapan ini adalah proses merancang user interface dan Code Generation, rancangan akan di implementasikan dalam pemrograman dengan menggunakan aplikasi software Atom, dan Bahasa pemrogaman yang digunakan adalah PHP, CSS, HTML. Coding atau pengkodean merupakan penerjemahan desain dalam bahasa yang bisa dikenali oleh komputer (Amrin, Larasati, \& Satriadi, 2020).

d. Pengujian

Pada tahapan ini akan dilakukan pengujian program yang berfungsi untuk menemukan kesalahan pada program. Pengujian program aplikasi dilakukan dengan menggunakan black box testing agar dapat memeriksa dan memastikan bahwa aplikasi yang telah dibuat sudah berfungsi dengan benar sesuai dengan rancangan sistem (Iriadi, Priatno, Ishaq, \& Yulianti, 2019).

\section{HASIL DAN PEMBAHASAN}

\section{Proses Bisnis}

Diawali ketika pemilik kapal menghubungi shipbroker melalui email untuk menawarkan kapalnya yang akan disewakan. Disisi lain penyewa kapal juga menghubungi shipbroker tersebut melalui email untuk dicarikan kapal yang akan disewakan. Setelah itu shipbroker bertugas untuk mencarikan dan mencocokkan kebutuhan kapal antara penyewa dan pemilik kapal. Apabila kriteria kapal yang dibutuhkan sudah cocok dengan pemilik kapal atau penyewa kapal, terjadilah komunikasi berupa negosiasi harga kapal yang disewakan. Apabila harga sewa kapal sudah sesuai dengan kedua belah pihak maka dilanjutkan dengan memberitahukan posisi kapal terakhir berada kemudian memberikan dokumen-dokumen seperti 
sertifikat kapal kepada pihak penyewa. Lalu membuat draf kontrak sewa menyewa kapal yang berisikan persyaratan dan ketentuan kesepakatan antara kedua belah pihak. Dan yang terakhir apabila semua telah disetujui kedua belah pihak dilanjutkan dengan pembuatan kontrak sewa menyewa kapal secara resmi.

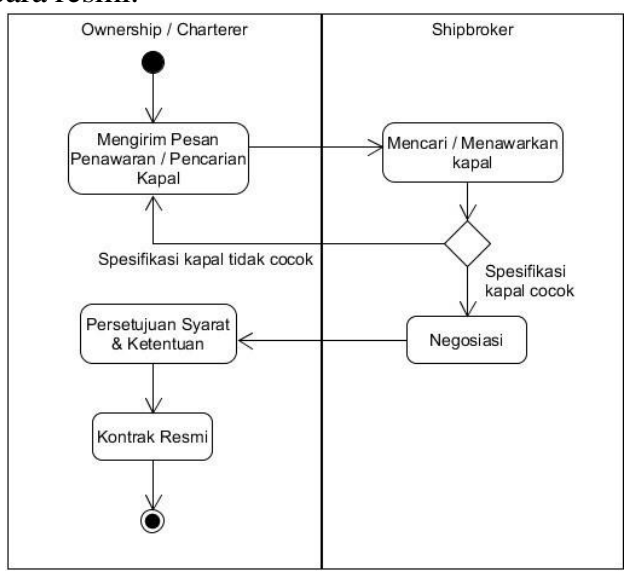

Sumber: (Hidayatulloh, Radiyah, \& Umma, 2021)

Gambar 2. Activity Diagram proses bisnis shipbroker \& Chartering

2. Analisa Kebutuhan Software

a. Tahapan analisis

Pada aplikasi shipbroker berbasis web ini terbagi menjadi dua hak akses yaitu admin dan user. Yang dimana admin sudah tidak perlu lagi mencocokan permintaan kebutuhan kapal dikarnakan sudah dipermudah oleh website dan user sudah dapat mencari sendiri sesuai kebutuhan kapal di website tersebut.

Halaman user:

A1. User dapat membuat akun.

A2. Member dapat melakukan login ke website. A3. Member dapat menawarkan kapal di website.

A4. Member dapat mencari kapal di website. A5. Member dapat mengirim pesan ke Member lain dan admin.

A6. Member dapat mengganti kata sandi.

A7. Member dapat memperbarui data diri.

Halaman admin:

B1. Admin dapat melakukan login ke website.

B2. Admin dapat menambahkan, mensunting, dan menghapus artikel.

B3. Admin dapat mengetujui penawaran atau pencarian kapal dari Member di website.

B4. Admin dapat menambahkan, mensunting, dan menghapus kategori kapal.

B5. Admin dapat menambahkan, mensunting, dan menghapus lokasi kapal.

B6. Admin dapat mengaktifkan, menonaktifkan, dan menghapus Member.

B7. Admin dapat membalas pesan dari Member.

b. Use Case

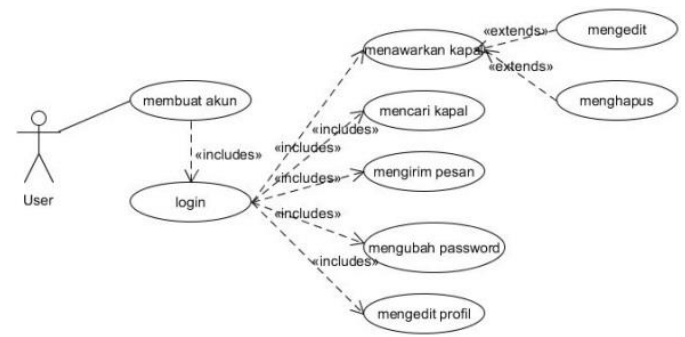

Sumber: (Hidayatulloh et al., 2021)

Gambar 3. Use Case Diagram halaman user

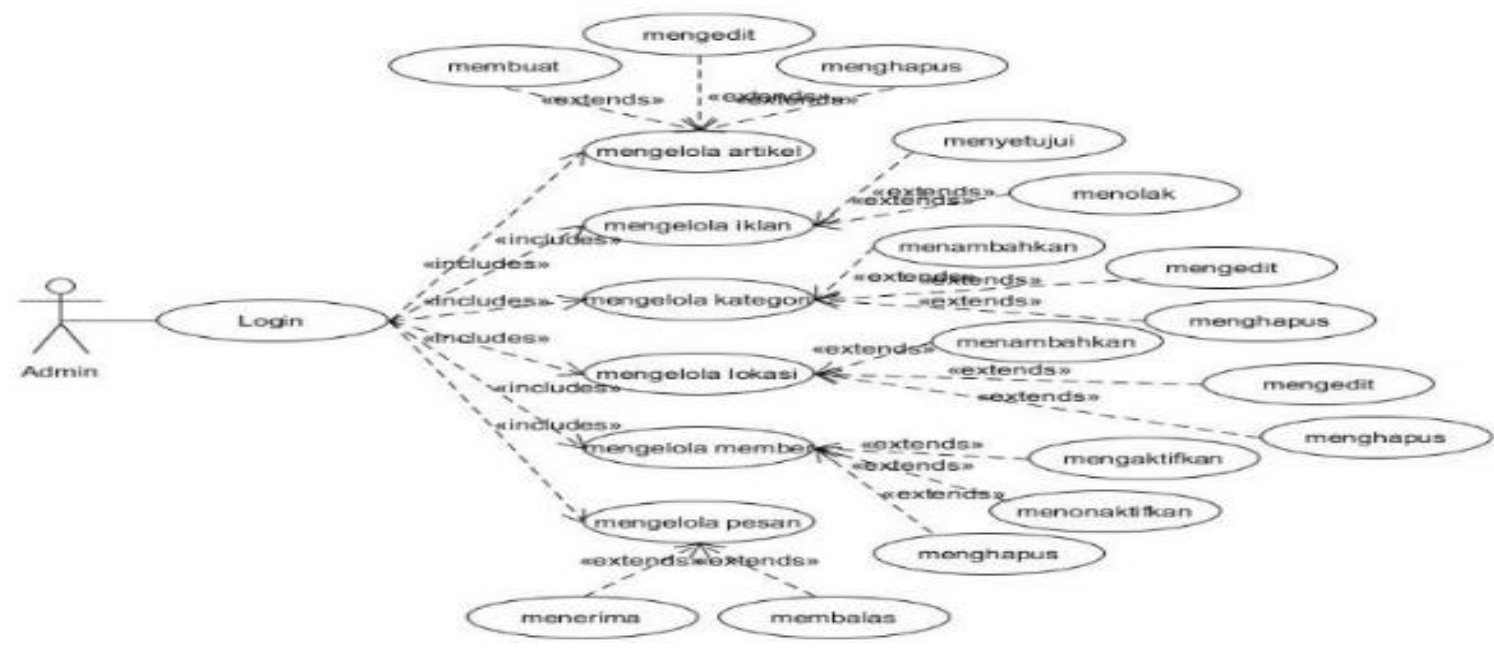

Sumber: (Hidayatulloh et al., 2021)

Gambar 4. Use Case Diagram halaman admin 
c. Activity Diagram

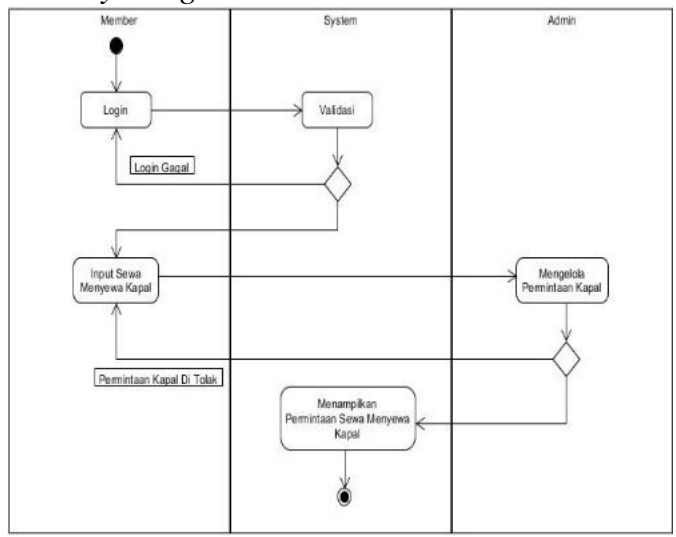

Sumber: (Hidayatulloh et al., 2021)

Gambar 5. Activity member penawaran kapal

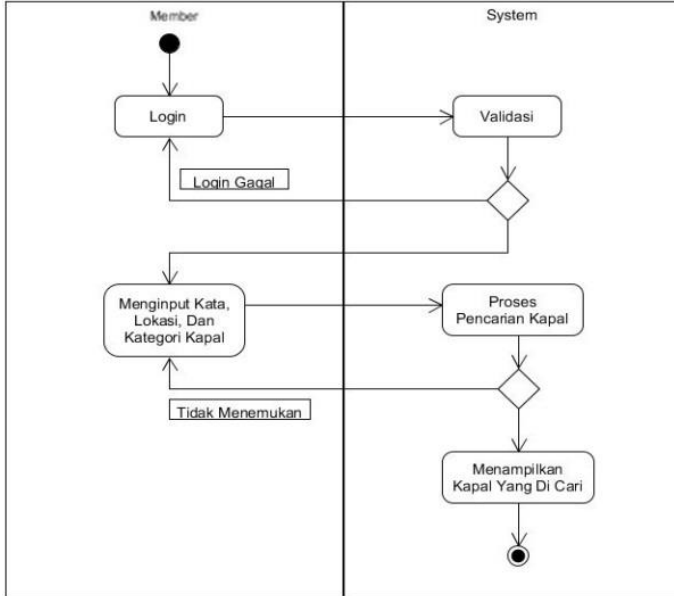

Sumber: (Hidayatulloh et al., 2021)

Gambar 6. Activity member mencari kapal

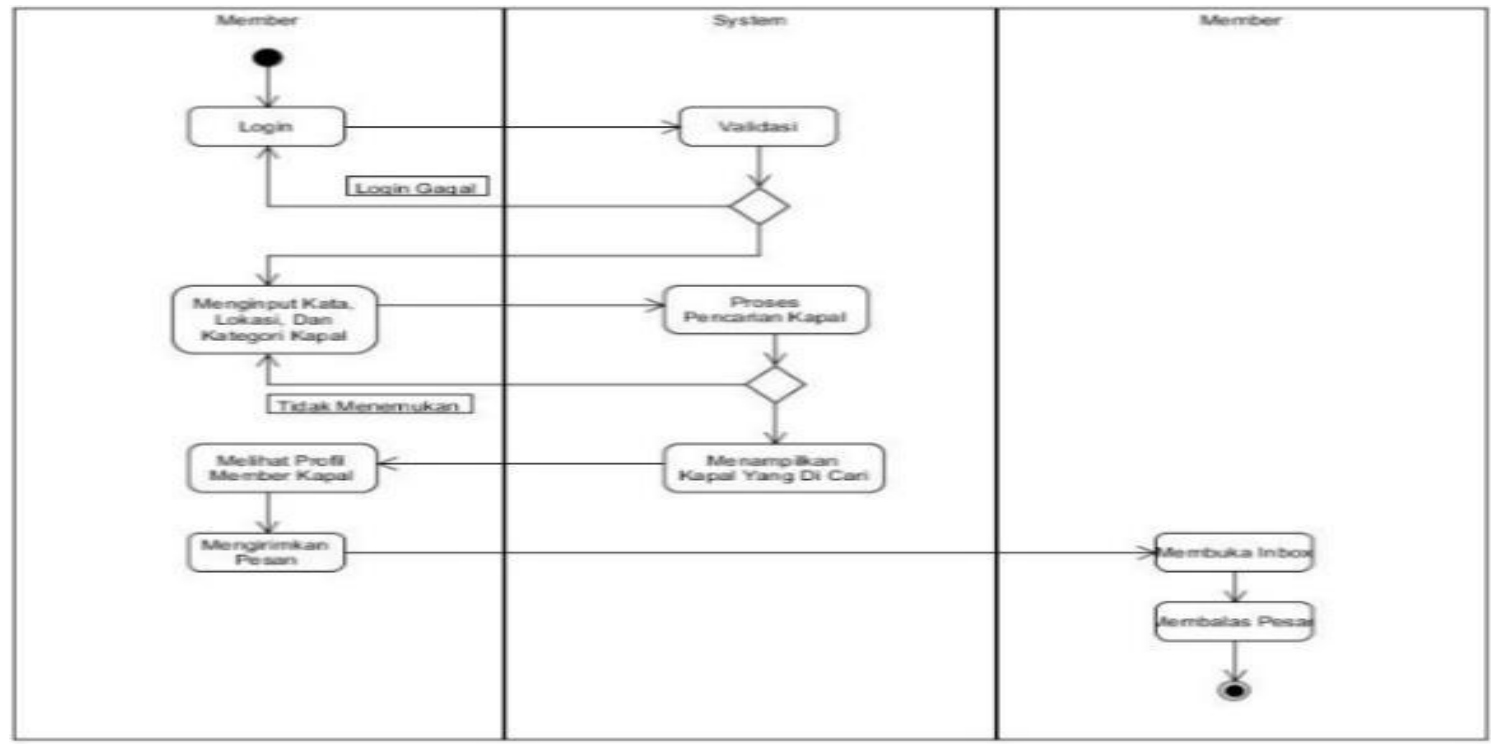

Sumber: (Hidayatulloh et al., 2021)

Gambar 7. Activity member mengirim pesan

\section{Desain}

a. Database

Entity Relationship Diagram adalah suatu pemodelan dari basis data relasional yang didasarkan atas persepsi di dalam dunia nyata, dunia ini senantiasa terdiri dari sekumpulan objek yang saling berhubungan antara satu dengan yang lainnya (Yasin, 2012). 


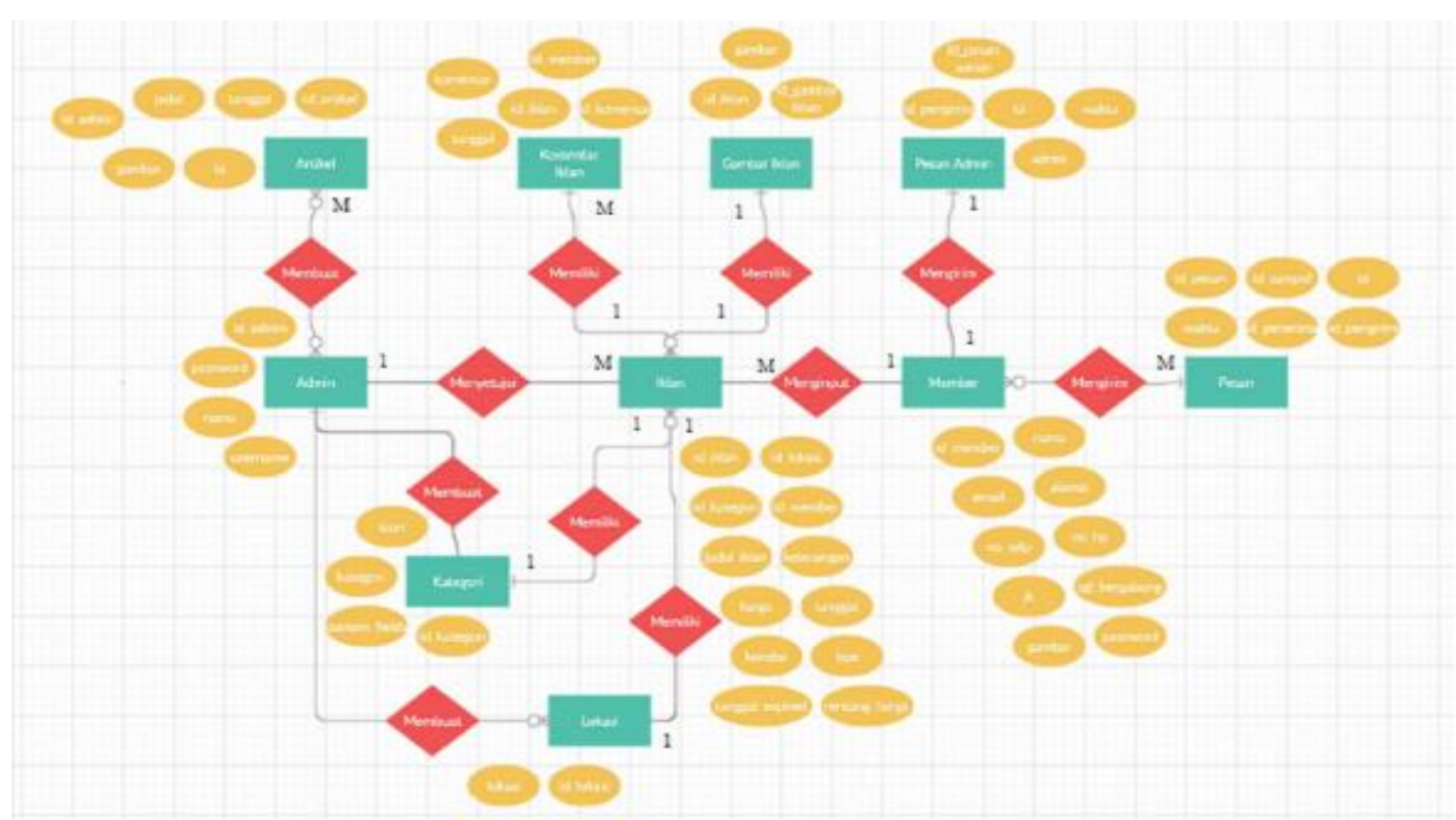

Sumber: (Hidayatulloh et al., 2021)

Gambar 8. Entity Relationship Diagram Sistem Informasi Shipbroker

b. Logical Record Structure (LRS)
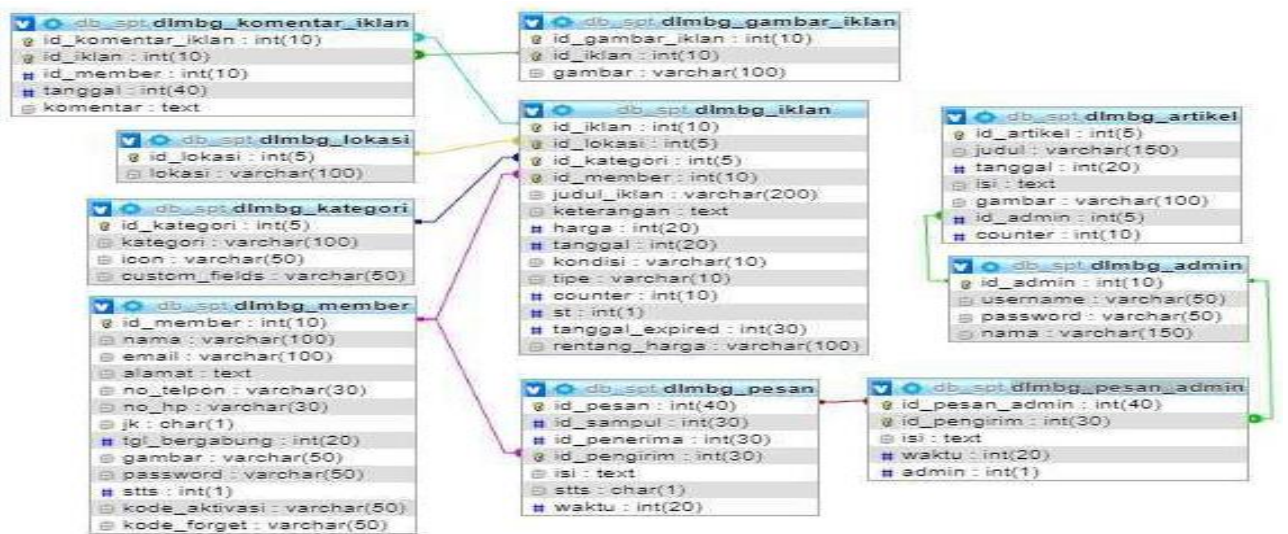

Sumber: (Hidayatulloh et al., 2021)

Gambar 9. Logical Record Structure sistem informasi shipbroker

c. Software Architecture

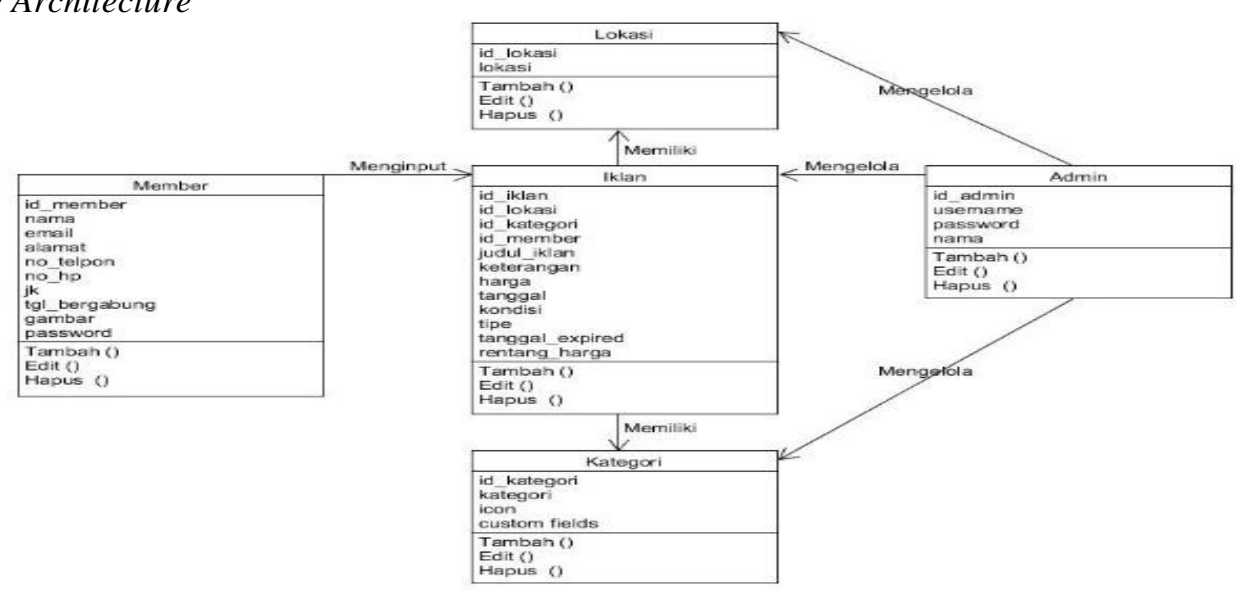

Sumber: (Hidayatulloh et al., 2021)

Gambar 10. Class Diagram Sistem Informasi shipbroker 


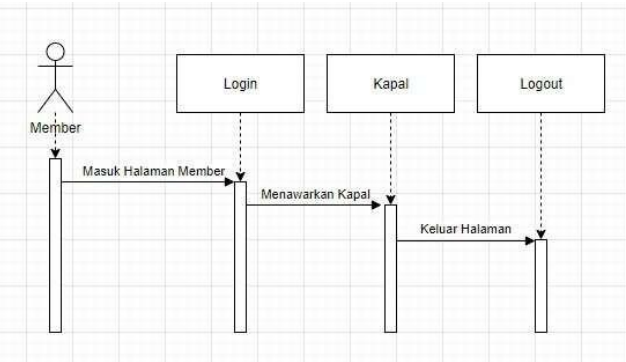

Sumber: (Hidayatulloh et al., 2021)

Gambar 11. Sequence Diagram input sewa menyewa kapal

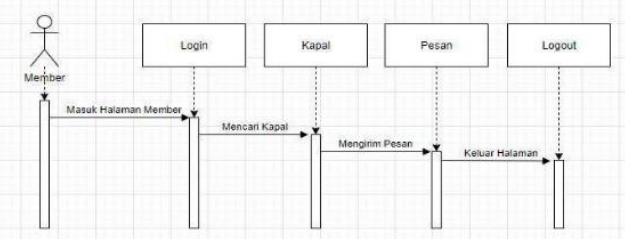

Sumber: (Hidayatulloh et al., 2021)

Gambar 12. Sequence Diagram pencarian kapal

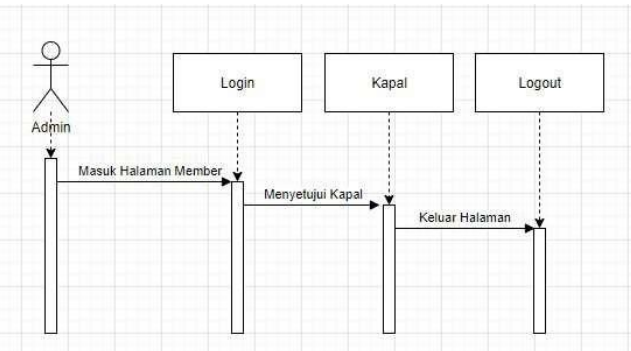

Sumber: (Hidayatulloh et al., 2021)

Gambar 13. Sequence Diagram mengelola sewa menyewa kapal

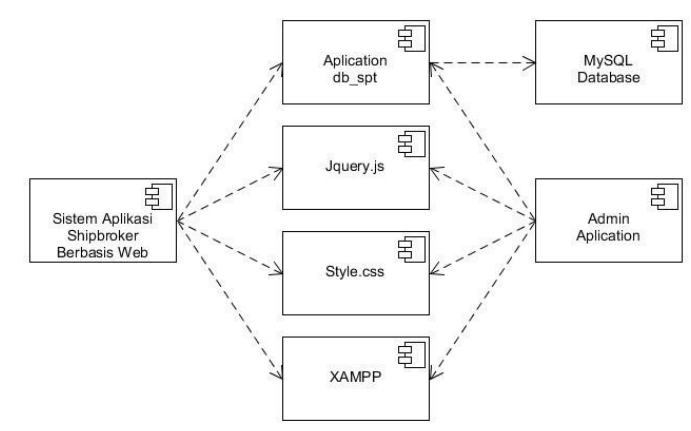

Sumber: (Hidayatulloh et al., 2021)

Gambar 14. Component Diagram Sistem informasi shipbroker

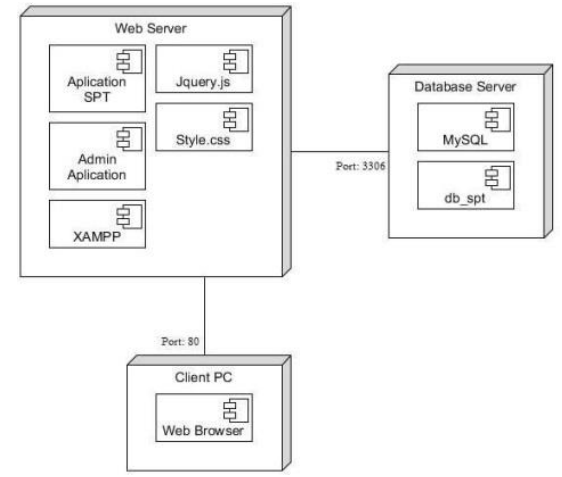

Sumber: (Hidayatulloh et al., 2021)

Gambar 15. Deployment Diagram Sistem informasi shipbroker

\section{Implementasi}

a. User Interface

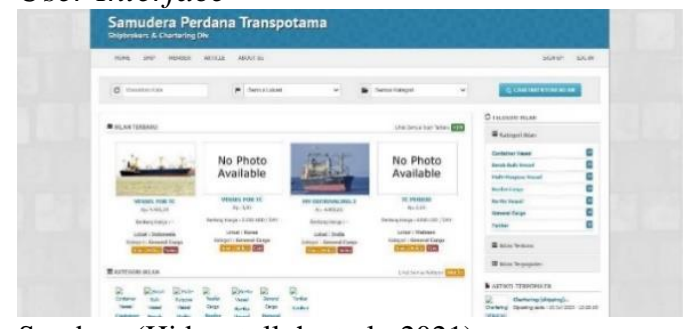

Sumber: (Hidayatulloh et al., 2021)

Gambar 16. Tampilan home sistem informasi shipbroker

Gambar 16 menunjukkan tampilan halam utama dari web sistem informasi shipbroker.

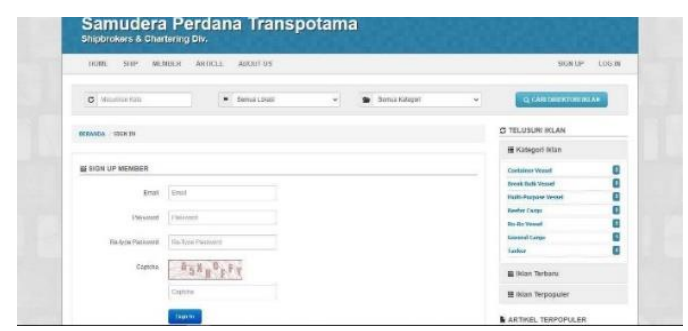

Sumber: (Hidayatulloh et al., 2021)

Gambar 17. Tampilan sign up member

Gambar diatas menampilkan halaman untuk pengguna membuat akun dalam sistem informasi shipbroker.

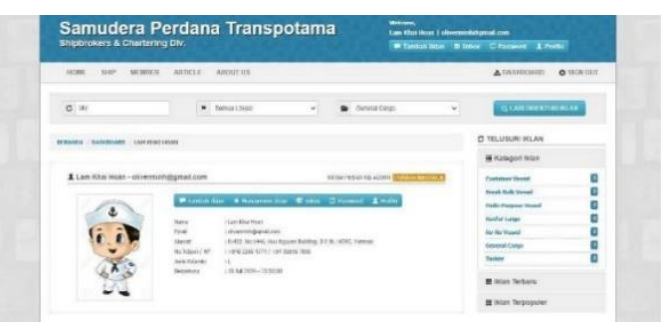

Sumber: (Hidayatulloh et al., 2021)

Gambar 18. Tampilan dashboard member

Pada gambar 18 menampilkan halaman utama atau dashboard bagi member sistem informasi shipbroker. 


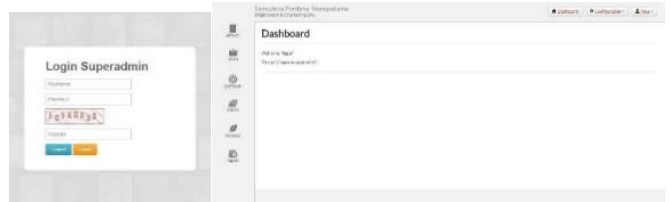

Sumber: (Hidayatulloh et al., 2021)

Gambar 19. Tampilan login dan dashboard admin

Halaman login bagi admin dan dashboard atau halaman utama admin dapat dilihat pada gambar 19.

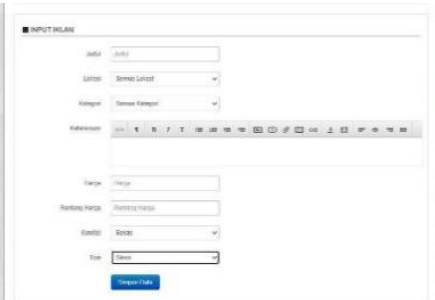

Sumber: (Hidayatulloh et al., 2021)

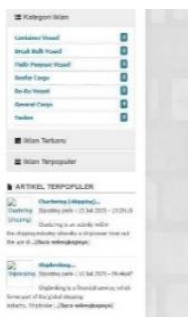

Gambar 20. Tampilan input sewa menyewa kapal

Gambar 20 merupakan tampilan halaman input transaksi sewa menyea kapal.

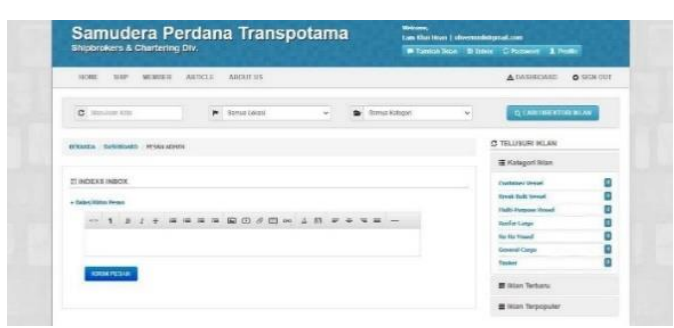

Sumber: (Hidayatulloh et al., 2021)

Gambar 21. Tampilan kirim pesan

Member maupun admin dapat berkirim pesan pada sistem informasi ini, gambar 21 menampilkan halaman berkirim pesan pada sistem informasi shipbroker.

b. Code Generation
$<$ ?php if ( ! defined('BASEPATH'))

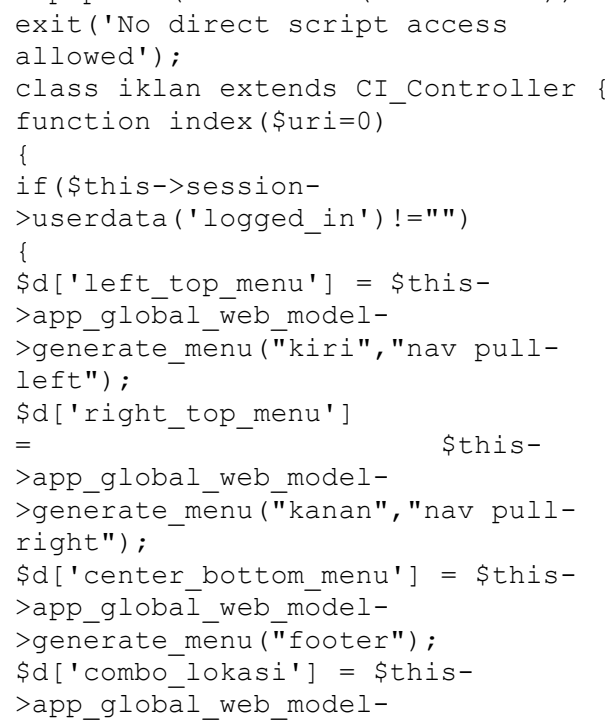

>app_global_web_model-

Code Generation
<?php if (! defined('BASEPATH'))

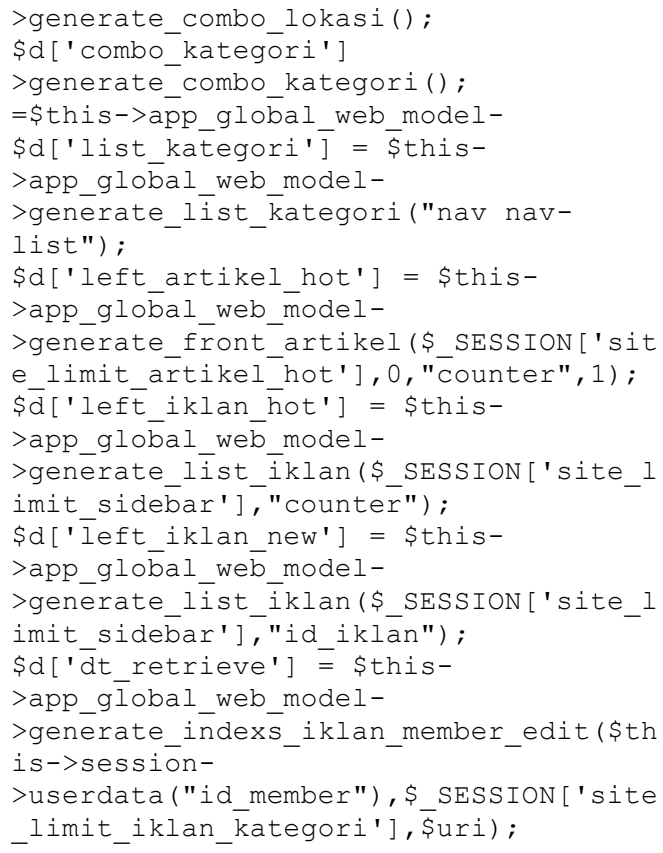

\section{Pengujian}

Tabel 1. Hasil pengujian black box form daftar

\begin{tabular}{|c|c|c|c|c|c|}
\hline \multicolumn{6}{|c|}{ member } \\
\hline No & $\begin{array}{c}\text { Skenari } \\
\mathrm{o}\end{array}$ & $\begin{array}{c}\text { Kasus } \\
\text { Penguiia }\end{array}$ & $\begin{array}{l}\text { Hasil yang } \\
\text { diharapkan }\end{array}$ & $\begin{array}{c}\text { Hasil } \\
\text { penguiia }\end{array}$ & $\begin{array}{c}\text { Kesimpul } \\
\text { an }\end{array}$ \\
\hline $\begin{array}{l}1 \\
\text {. }\end{array}$ & $\begin{array}{l}\text { Semua } \\
\text { data } \\
\text { member } \\
\text { tidak di } \\
\text { isi }\end{array}$ & $\begin{array}{l}\text { Nama, } \\
\text { Email, } \\
\text { Alamat, } \\
\text { No HP, } \\
\text { Passwor } \\
d, \text { JK: } \\
\text { (kosong } \\
\text { ) }\end{array}$ & $\begin{array}{l}\text { Sistem } \\
\text { akan } \\
\text { menampilk } \\
\text { an pesan } \\
\text { "please fill } \\
\text { out this } \\
\text { field." }\end{array}$ & $\begin{array}{l}\text { Sesuai } \\
\text { yang } \\
\text { diharapk } \\
\text { an }\end{array}$ & Valid \\
\hline 2 & $\begin{array}{l}\text { Semua } \\
\text { data } \\
\text { member } \\
\text { di isi }\end{array}$ & $\begin{array}{l}\text { Nama, } \\
\text { Email, } \\
\text { Alamat, } \\
\text { No HP, } \\
\text { Passwor } \\
\text { d, JK: } \\
\text { (diisi) }\end{array}$ & $\begin{array}{l}\text { Sistem } \\
\text { akan } \\
\text { memproses } \\
\text { dan } \\
\text { menampilk } \\
\text { an pesan } \\
\text { "Email } \\
\text { verifikasi } \\
\text { telah } \\
\text { terkirim ke } \\
\text { email } \\
\text { anda" }\end{array}$ & $\begin{array}{l}\text { Sesuai } \\
\text { yang } \\
\text { diharapk } \\
\text { an }\end{array}$ & Valid \\
\hline 3 & $\begin{array}{l}\text { Semua } \\
\text { data } \\
\text { member } \\
\text { di isi } \\
\text { dengan } \\
\text { yang } \\
\text { sudah } \\
\text { ada }\end{array}$ & $\begin{array}{l}\text { Nama, } \\
\text { Email, } \\
\text { Alamat, } \\
\text { No HP, } \\
\text { Passwor } \\
\text { d, JK: } \\
\text { (diisi } \\
\text { dengan } \\
\text { yang } \\
\text { sudah } \\
\text { terdaftar } \\
\text { ) }\end{array}$ & $\begin{array}{l}\text { Sistem } \\
\text { akan } \\
\text { menampilk } \\
\text { an pesan } \\
\text { "Email } \\
\text { telah } \\
\text { terpakai" }\end{array}$ & $\begin{array}{l}\text { Sesuai } \\
\text { yang } \\
\text { diharapk } \\
\text { an }\end{array}$ & Valid \\
\hline
\end{tabular}

Sumber: (Hidayatulloh et al., 2021)

Tabel 2. Hasil pengujian black box form login member

\begin{tabular}{|c|c|c|c|c|c|}
\hline No & $\begin{array}{c}\text { Skenari } \\
\mathrm{o} \\
\text { penguji } \\
\text { an }\end{array}$ & $\begin{array}{c}\text { Kasus } \\
\text { Pengujia } \\
\mathrm{n}\end{array}$ & $\begin{array}{c}\text { Hasil yang } \\
\text { diharapkan }\end{array}$ & $\begin{array}{c}\text { Hasil } \\
\text { penguji } \\
\text { an }\end{array}$ & $\begin{array}{c}\text { Kesimpul } \\
\text { an }\end{array}$ \\
\hline
\end{tabular}




\begin{tabular}{|c|c|c|c|c|c|}
\hline No & $\begin{array}{c}\text { Skenari } \\
\text { o } \\
\text { penguji } \\
\text { an }\end{array}$ & $\begin{array}{c}\text { Kasus } \\
\text { Pengujia } \\
\mathrm{n}\end{array}$ & $\begin{array}{l}\text { Hasil yang } \\
\text { diharapkan }\end{array}$ & $\begin{array}{c}\text { Hasil } \\
\text { penguji } \\
\text { an }\end{array}$ & $\begin{array}{c}\text { Kesimpul } \\
\text { an }\end{array}$ \\
\hline 1 & $\begin{array}{l}\text { Semua } \\
\text { kolom } \\
\text { pada } \\
\text { halama } \\
\text { login } \\
\text { tidak } \\
\text { diisi }\end{array}$ & $\begin{array}{l}\text { Usernam } \\
e, \\
\text { Passwor } \\
d, \\
\text { Captcha: } \\
\text { (kosong) }\end{array}$ & $\begin{array}{l}\text { Sistem } \\
\text { akan } \\
\text { menampilk } \\
\text { an pesan } \\
\text { "please fill } \\
\text { out this } \\
\text { field." }\end{array}$ & $\begin{array}{l}\text { Sesuai } \\
\text { harapan }\end{array}$ & Valid \\
\hline 2 & $\begin{array}{l}\text { Semua } \\
\text { kolom } \\
\text { pada } \\
\text { halama } \\
\mathrm{n} \text { login } \\
\text { di isi } \\
\text { dengan } \\
\text { benar }\end{array}$ & $\begin{array}{l}\text { Usernam } \\
e: \\
\text { (benar) } \\
\text { Passwor } \\
d: \\
\text { (benar) } \\
\text { Captcha: } \\
\text { (benar) }\end{array}$ & $\begin{array}{l}\text { Sistem } \\
\text { akan } \\
\text { memberika } \\
\mathrm{n} \text { akses } \\
\text { masuk ke } \\
\text { menu } \\
\text { halaman } \\
\text { member }\end{array}$ & $\begin{array}{l}\text { Sesuai } \\
\text { harapan }\end{array}$ & Valid \\
\hline 3 & $\begin{array}{l}\text { satu } \\
\text { kolom } \\
\text { login } \\
\text { tidak } \\
\text { diisi } \\
\text { dengan } \\
\text { benar }\end{array}$ & $\begin{array}{l}\text { Usernam } \\
e: \\
\text { (benar) } \\
\text { Passwor } \\
d: \\
\text { (selah) } \\
\text { Captcha: } \\
\text { (benar) }\end{array}$ & $\begin{array}{l}\text { Sistem } \\
\text { akan } \\
\text { menampilk } \\
\text { an pesan } \\
\text { "Gagal } \\
\text { Login, } \\
\text { Email dan } \\
\text { password } \\
\text { Tidak } \\
\text { Cocok...." }\end{array}$ & $\begin{array}{l}\text { Sesuai } \\
\text { harapan }\end{array}$ & Valid \\
\hline
\end{tabular}

Sumber: (Hidayatulloh et al., 2021)

Tabel 3. Hasil pengujian black box form sewa menyewa

\begin{tabular}{|c|c|c|c|c|c|}
\hline No. & $\begin{array}{c}\text { Skenari } \\
\text { o } \\
\text { penguji } \\
\text { an } \\
\end{array}$ & $\begin{array}{c}\text { Kasus } \\
\text { Pengujian }\end{array}$ & $\begin{array}{l}\text { Hasil yang } \\
\text { diharapkan }\end{array}$ & $\begin{array}{c}\text { Hasil } \\
\text { penguji } \\
\text { an }\end{array}$ & $\begin{array}{c}\text { Kesimpul } \\
\text { an }\end{array}$ \\
\hline 1 & $\begin{array}{l}\text { Judul } \\
\text { kolom } \\
\text { inputan } \\
\text { tidak } \\
\text { diisi }\end{array}$ & 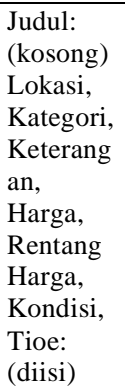 & $\begin{array}{l}\text { Sistem } \\
\text { akan } \\
\text { menampilk } \\
\text { an pesan } \\
\text { "please fill } \\
\text { out this } \\
\text { field." }\end{array}$ & $\begin{array}{l}\text { Sesuai } \\
\text { Harapa } \\
\text { n }\end{array}$ & Valid \\
\hline 2 & $\begin{array}{l}\text { Semua } \\
\text { kolom } \\
\text { inputan } \\
\text { di isi } \\
\text { dengan } \\
\text { benar }\end{array}$ & $\begin{array}{l}\text { Judul, } \\
\text { Lokasi, } \\
\text { Kategori, } \\
\text { Keterang } \\
\text { an, } \\
\text { Harga, } \\
\text { Rentang } \\
\text { Harga, } \\
\text { Kondisi, } \\
\text { Tioe: } \\
\text { (diisi) }\end{array}$ & $\begin{array}{l}\text { Sistem } \\
\text { akan } \\
\text { memprose } \\
\mathrm{s} \text {, dan hasil } \\
\text { inputan } \\
\text { menunggu } \\
\text { persetujua } \\
\mathrm{n} \text { admin }\end{array}$ & $\begin{array}{l}\text { Sesuai } \\
\text { Harapa } \\
\text { n }\end{array}$ & Valid \\
\hline
\end{tabular}

Sumber: (Hidayatulloh et al., 2021)

Tabel 4. Hasil Pengujian Black Box Testing Form

\begin{tabular}{|c|c|c|c|c|c|}
\hline No & $\begin{array}{c}\text { Skenari } \\
\text { o } \\
\text { penguji } \\
\text { an }\end{array}$ & $\begin{array}{c}\text { Kasus } \\
\text { Pengujia } \\
\text { n }\end{array}$ & $\begin{array}{c}\text { Hasil yang } \\
\text { diharapkan }\end{array}$ & $\begin{array}{c}\text { Hasil } \\
\text { penguji } \\
\text { an }\end{array}$ & $\begin{array}{c}\text { Kesimpul } \\
\text { an }\end{array}$ \\
\hline
\end{tabular}

\begin{tabular}{|c|c|c|c|c|c|}
\hline No & $\begin{array}{c}\text { Skenari } \\
\text { o } \\
\text { penguji } \\
\text { an } \\
\end{array}$ & $\begin{array}{c}\text { Kasus } \\
\text { Pengujia } \\
\text { n }\end{array}$ & $\begin{array}{l}\text { Hasil yang } \\
\text { diharapkan }\end{array}$ & $\begin{array}{l}\text { Hasil } \\
\text { penguji } \\
\text { an }\end{array}$ & $\begin{array}{c}\text { Kesimpul } \\
\text { an }\end{array}$ \\
\hline 1 & $\begin{array}{l}\text { Semua } \\
\text { kolom } \\
\text { login } \\
\text { tidak } \\
\text { diisi }\end{array}$ & $\begin{array}{l}\text { Usernam } \\
\text { e, } \\
\text { Passwor } \\
d, \\
\text { Captcha: } \\
\text { (kosong) }\end{array}$ & $\begin{array}{l}\text { Sistem } \\
\text { akan } \\
\text { menampilk } \\
\text { an pesan } \\
\text { "please fill } \\
\text { out this } \\
\text { field." }\end{array}$ & $\begin{array}{l}\text { Sesuai } \\
\text { Harapa } \\
\mathrm{n}\end{array}$ & Valid \\
\hline 2 & $\begin{array}{l}\text { Semua } \\
\text { kolom } \\
\text { login di } \\
\text { isi } \\
\text { dengan } \\
\text { benar }\end{array}$ & $\begin{array}{l}\text { Usernam } \\
\text { e: } \\
\text { (benar) } \\
\text { Passwor } \\
d: \\
\text { (benar) } \\
\text { Captcha: } \\
\text { (benar) }\end{array}$ & $\begin{array}{l}\text { Sistem } \\
\text { akan } \\
\text { memberika } \\
\mathrm{n} \text { akses } \\
\text { masuk ke } \\
\text { menu } \\
\text { halaman } \\
\text { admin }\end{array}$ & $\begin{array}{l}\text { Sesuai } \\
\text { Harapa } \\
\mathrm{n}\end{array}$ & Valid \\
\hline 3 & $\begin{array}{l}\text { Satu } \\
\text { kolom } \\
\text { login } \\
\text { tidak } \\
\text { diisi } \\
\text { dengan } \\
\text { benar }\end{array}$ & $\begin{array}{l}\text { Usernam } \\
\text { e: (salah) } \\
\text { Passwor } \\
d \text { : } \\
\text { (benar) } \\
\text { Captcha: } \\
\text { (benar) }\end{array}$ & $\begin{array}{l}\text { Sistem } \\
\text { akan } \\
\text { menampilk } \\
\text { an pesan } \\
\text { "Username } \\
\text { dan } \\
\text { password } \\
\text { Tidak } \\
\text { Cocok...." }\end{array}$ & $\begin{array}{l}\text { Sesuai } \\
\text { Harapa } \\
\mathrm{n}\end{array}$ & Valid \\
\hline
\end{tabular}

Sumber: (Hidayatulloh et al., 2021)

\section{KESIMPULAN}

Dari hasil penelitian yang dilakukan dapat disimpulkan bahwa hasil pengujian sistem informasi shipbroker menunjukkan bahwa sistem informasi tersebut dapat berfungsi sesuai dengan perancangan yang telah direncanakan. Selain itu sistem ini memiliki kelebihan dimana member dapat mencari sendiri kapal yang ingin di sewa (sesuai kebutuhan) melalui fitur pencarian kapal dan dapat menawarkan kapalnya apabila disewakan secara komersil. Sistem informasi ini dapat memberi kemudahan kepada semua pengguna baik dari sisi perusahaan maupun dari sisi customer.

\section{REFERENSI}

Amrin, Larasati, M. D., \& Satriadi, I. (2020). Model Waterfall Untuk Pengembangan Sistem Informasi Pengolahan Nilai Pada SMP Kartika XI-3 Jakarta Timur. Jurnal Teknik Komputer Amik Bsi, VI(1), 135-140. https://doi.org/10.31294/jtk.v4i2

Ariani Sukamto, R., \& Shalahuddin, M. (2013). Rekayasa perangkat lunak: terstruktur dan berorientasi objek. Bandung: Informatika.

Ayu, F., \& Permatasari, N. (2018). perancangan sistem informasi pengolahan data PKL pada divisi humas PT pegadaian. Jurnal IntraTechtech, 2(2), 12-26. Retrieved from http://journal.amikmahaputra.ac.id/index.php/J IT/article/download/33/25

Gunadi, D. C. A., \& Zakaria, T. M. (2018). Perancangan E-Marketplace Sewa-Menyewa 
sebagai Alternatif Bisnis di Era Digital. Teknik Informatika Dan Sistem Informasi, 4(EMarketplace), 279-291. Retrieved from https://journal.maranatha.edu/index.php/jutisi/ article/view/1495

Hidayatulloh, S., Radiyah, U., \& Umma, F. K. (2021). Rancang Bangun Sistem Informasi Shipbroker Sebagai Media Transaksi Sewa Menyewa Kapal Berbasis Web. Jakarta.

Iriadi, N., Priatno, Ishaq, A., \& Yulianti, Wi. (2019). Sistem Informasi Penyewaan Lapangan Futsal Berbasis Web Pada Futsal Station Bekasi. Indonesian Journal on Networking and Security, $8(4), \quad 1-8$. https://doi.org/10.23887/jptkundiksha.v16i1.16483

Pranata, D., Hamdani, H., \& Khairina, D. M. (2015). Rancang Bangun Website Jurnal Ilmiah Bidang Komputer (Studi Kasus: Program Studi Ilmu Komputer Universitas Mulawarman). Informatika Mulawarman: Jurnal Ilmiah Ilmu Komputer, 10(2), 25. https://doi.org/10.30872/jim.v10i2.187

Susilo, M., \& Kurniati, R. (2018). RANCANG BANGUN WEBSITE TOKO ONLINE MENGGUNAKAN METODE
WATERFALL. InfoTekJar, 2(2), 98-105. Retrieved from https://jurnal.uisu.ac.id/index.php/infotekjar/ar ticle/view/171/pdf

Tristianto, C. (2018). PENGGUNAAN METODE WATERFALL UNTUK PENGEMBANGAN SISTEM MONITORING DAN EVALUASI PEMBANGUNAN PEDESAAN. Jurnal Teknologi Informasi ESIT, XII(1), 8-22. https://doi.org/10.1093/nq/182.23.321-a

Yasin, V. (2012). Rekayasa Perangkat Lunak Berorientasi Objek. Jakarta: Mitra Wacana Media.

Zahra, F. A., Pradana, F., \& Jonemaro, E. M. A. (2019). Pengembangan Aplikasi Portal Penyewaan Barang di Kota Malang Berbasis Web. Jurnal Pengambangan Teknologi Informasi Dan Ilmu Komputer, 3(7), 70437050. Retrieved from http://jptiik.ub.ac.id/index.php/jptiik/article/view/5853 